\title{
DISEMINASI ILMU PERTOLONGAN PERTAMA KECELAKAAN PADA ANAK DI RUMAH PADA WILAYAH KERJA PUSKESMAS AMBACANG
}

\author{
Dwi Novrianda $^{1 *}$, Hermalinda ${ }^{1}$, Deswita $^{1}$, Lili Fajria $^{1}$, Meri Neherta $^{1}, \operatorname{Vetty~Priscilla~}^{1}$, \\ Yonrizal Nurdin ${ }^{2}$ \\ ${ }^{1}$ Bagian Keperawatan Anak-Maternitas, Fakultas Keperawatan Universitas Andalas \\ ${ }^{2}$ Bagian Keperawatan Jiwa, Komunitas dan Keluarga, Fakultas Keperawatan Universitas \\ Andalas, \\ ${ }^{*}$ Email: dwinovrianda@nrs.unand.ac.id
}

\begin{abstract}
ABSTRAK
Puskesmas Ambacang merupakan satu dari tiga fasilitas pelayanan kesehatan tingkat 1 di Kecamatan Kuranji Kota Padang. Puskesmas Ambacang meliputi 4 kelurahan sebagai wilayah kerjanya. Wilayah kerja Puskesmas ini berada di pusat kota dan di pinggir jalan utama sehingga beresiko terjadinya berbagai kejadian yang dapat mencederai pada balita akibat kecelakaan lalu lintas maupun kecelakaan selama berada di dalam rumah. Mitra pada kegiatan ini yaitu kelompok keluarga di Kelurahan Anduring sebanyak 20 orang. Permasalahan mitra yang dirumuskan yaitu rendahnya pengetahuan dan keterampilan dalam mengidentifikasi cedera pada anak dan upaya antisipasi yang dapat dilakukan di rumah sebagai akibat kurangnya wawasan dan keterampilan tentang panduan antisipasi cedera. Oleh karena itu pemberian edukasi kesehatan merupakan salah satu alternatif yang dapat diberikan. Setelah diberikan edukasi kesehatan telah dapat meningkatkan wawasan dan ilmu pengetahuan mengenai identifikasi dan penanganan cedera pada anak yang sangat penting dalam membangun sikap yang positif dan membentuk perilaku yang tepat sehingga dapat menjadi karakter sebagai caregiver anak.
\end{abstract}

Kata Kunci: cedera, edukasi kesehatan, panduan antisipasi

\section{Dissemination of First Aid Science in Accidents in Children in The Working Area of Ambacang Health Center}

\begin{abstract}
The Ambacang Public Health Center (PHC) is one of three level 1 health care facilities in Kuranji Sub-District, Padang City. It covers 4 urban villages as its working area. The working area of the PHC is in the center of the city and on the edge of the main road so there is a risk of various events that can injure under-five children due to traffic accidents or accidents while in the house. This partner in communitybased science and technology (CBST) is a family group of 20 people in Anduring Village. The partner problems that were formulated were the lack of knowledge and skills in identifying injuries to children and anticipation efforts that could be made at home as a result of a lack of insight and skills about guideline for anticipating injuries. Therefore the provision of health education is an alternative that can be given. Having been given health education has been able to improve knowledge regarding the identification and handling of injuries to children which is very important in building a positive attitude and forming the right behavior so that it can become a character as a child caregiver.
\end{abstract}

Keywords: injury, health education, anticipatory guidance

\section{PENDAHULUAN}

Puskesmas Ambacang merupakan satu dari tiga fasilitas pelayanan kesehatan tingkat 1 di Kecamatan Kuranji Kota Padang. Puskesmas Ambacang meliputi 4 kelurahan sebagai wilayah kerjanya dari sembilan kelurahan di Kecamatan Kuranji 
yaitu Kelurahan Pasar Ambacang, Kelurahan Anduring, Kelurahan Lubuk Lintah, dan Kelurahan Ampang. Puskesmas Ambacang terletak pada 0055'25.15"LS dan 0023'50.14"LU dengan luas wilayah kerja sekitar $12 \mathrm{Km}^{2}$. Batas-batas wilayah kerja Puskesmas Ambacang adalah sebagai berikut:

sebelah utara berbatasan dengan Kelurahan Korong Gadang, sebelah selatan berbatasan dengan Kecamatan Pauh dan Kecamatan Padang Timur, sebelah barat berbatasan dengan Kecamatan Padang Timur dan Kecamatan Nanggalo,

sebelah timur berbatasan dengan Kecamatan Pauh.

Fasilitas kesehatan yang berada di Puskesmas Ambacang tersebar di antaranya 1 Puskesmas Pembantu, 6 Posyandu Lansia, 2 Klinik Swasta, 28 Posyandu Balita dengan jumlah terbanyak (9 Posyandu Balita) berada di Kelurahan Pasar Ambacang, dan 12 Poskesdes/Poskeskel. Berdasarkan keputusan dari Depertemen Kesehatan RI tahun 2006 pelayanan di Posyandu mencakup lima kegiatan pelayanan kesehatan dasar yaitu pelayanan keluarga berencana, pelayanan kesehatan Ibu dan Anak, gizi dan tumbuh kembang anak, imunisasi dan penanggulangan diare (Depkes, 2006). Oleh karena itu, wilayah kerja puskesmas ini tepat untuk dilakukan kegiatan dengan target keluarga yang memiliki balita.

Wilayah kerja Puskesmas ini berada di pusat kota dan di pinggir jalan utama sehingga beresiko terjadinya berbagai kejadian yang dapat mencederai pada balita akibat kecelakaan lalu lintas maupun kecelakaan selama berada di dalam rumah. Setiap tahun di Indonesia hampir 1 juta anak meninggal karena kecelakaan dan lebih dari puluhan juta anak-anak lainnya memerlukan perawatan rumah sakit karena mengalami luka berat. Di antara yang luka berat banyak yang menjadi cacat permanen dan mendapat gangguan fungsi otak. Kecelakaan yang biasa terjadi adalah jatuh, terbakar, dan tenggelam. Umumnya kecelakaan terjadi di dekat rumah. Hampir semuanya dapat dicegah dan dapat diatasi jika orang tua tahu yang harus mereka lakukan untuk mencegah kecelakaan dan jika terjadi kecelakaan (Depkes RI, 2010).

Menurut Riskesdas (2013), di Propinsi Sumatera Barat, prevalensi kejadian cedera dan penyebabnya pada balita adalah sepeda motor $(8.8 \%)$, transportasi darat lainnya (2.6\%), jatuh (77.3\%), benda tajam atau tumpul (6.3\%), kejatuhan (2.4\%). Proporsi tempat terjadinya cedera pada balita adalah di rumah sekitar 87\%. Sementara itu, menurut Dinas Kesehatan Kota Padang (2016), prevalensi kejadian cedera pada toddler adalah jatuh (8.9\%), kecelakaan tenggelam (20.6\%), fraktur tulang (2.6\%), luka bakar $(5.3 \%)$, kemasukan benda asing (9.7\%), cedera yang tidak terduga (8.7\%), dan keracunan $(10.26 \%)$.

Di Indonesia upaya pemerintah untuk menurunkan angka kematian anak dengan mengikuti program berkelanjutan yang dikenal dengan Suitable Development Goals (SDGs) yang merupakan kelanjutan dari Milenium Development Goals (MDGs) yaitu sasaran keempat dengan tujuan menurunkan angka kematian anak, berbagai upaya yang dilaksanakan dalam rangka meningkatkan kesehatan anak Indonesia, yakni melalui continuum of care berdasarkan siklus hidup, continuum of care berdasarkan pelayanan kesehatan (promotif, preventif, kuratif, dan rehabilitatif), continuum of care pathway sejak anak di rumah, di masyarakat (pelayanan posyandu dan poskesdes), di fasilitas pelayanan kesehatan dasar, dan di fasilitas pelayanan kesehatan rujukan.

Umur dan jenis kelamin anak mempengaruhi kejadian cedera. Kebanyakan cedera 
tak sengaja terjadi pada anak di bawah 5 tahun dan terjadi di sekitar rumah dimana tempat toddler dan balita lebih banyak menghabiskan waktunya (Ablewhite et al., 2015). Sementara itu, toddler ialah anak yang usianya 12-36 bulan atau 1-3 tahun (Hockenberry \& Wilson, 2015) dan masa anak mengeksplorasi lingkungan yang intensif karena anak berusaha untuk mencari tahu bagaimana sesuatu dapat terjadi (Potter \& Perry, 2009). Toddler yang belajar berjalan tidak memiliki rasa takut dan mempunyai banyak rasa ingin tahu namun sering berada di dalam ruangan sehingga anak tersebut mudah terjatuh, mengalami luka bakar, dan keracunan akibat ulahnya sendiri. Oleh karena itu anak toddler berisiko tinggi mengalami kecelakaan. Kecelakaan pada toddler sering kali mengakibatkan kondisi yang fatal pada anak yaitu kematian. Kondisi yang dimaksud diantaranya tertabrak mobil, tenggelam, keracunan, jatuh dan luka bakar (Supartini, 2012). Selanjutnya anak laki-laki lebih beresiko tinggi terkena cedera daripada anak perempuan. Lingkungan, ras dan status sosial ekonomi juga faktor yang beresiko pada anak untuk terjadinya cedera (Behrman et al., 2012).

Faktor resiko sosial ekonomi yang merupakan salah satu faktor yang mempengaruhi cedera pada anak terkait akan pendidikan ibu (faktor sosial), pendapatan keluarga (faktor ekonomi), faktor yang berkaitan dengan struktur keluarga yaitu tipe keluarga seperti orang tua tunggal atau keluarga lengkap, ibu remaja atau usia ibu, anak urutan ke berapa, saudara kandung dan banyak jumlah anggota keluarga. Faktor yang berkaitan dengan akomodasi seperti seperti jenis perumahan, kepadatan penduduk dan kepemilikan rumah (WHO, 2008).

Cedera yang tidak sengaja pada balita dan toddler merupakan masalah yang serius, namun sebagian besar dapat dicegah. Program pencegahan menggunakan strategi multidisiplin (yaitu kombinasi antara pendidikan, modifikasi lingkungan, modifikasi produk, kunjungan rumah yang mendukung dan undang-undang) telah terbukti efektif dalam mengurangi angka kematian akibat cedera di negara berpendapatan tinggi (Megahed, 2015).

Identifikasi dan penanganan cedera anak yang tidak disengaja yang sering terlihat di rangkaian perawatan primer. Pencegahan cedera yang tidak disengaja melibatkan panduan antisipatif untuk membantu orang tua memberikan lingkungan yang aman bagi anak-anak mereka. Strategi untuk mencegah cedera pada anak sekarang berfokus pada pemahaman dan modifikasi faktor risiko, pengembangan pendekatan program di seluruh masyarakat, dan mempromosikan agenda poli, dan agenda legislatif yang berfokus pada pencegahan cedera (Burns et al., 2009).

Berdasarkan permasalahan tersebut perlu dilakukan upaya penanganan antisipasi cedera pada toddler oleh keluarga di rumah melalui upaya kombinasi antara pendidikan dan modifikasi lingkungan. Tujuan kegiatan ini adalah 1) meningkatkan pengetahuan mitra tentang defenisi, klasifikasi cedera dan identifikasi masalah atau lingkungan yang menimbulkan cedera pada anak serta upaya pencegahan dan penatalaksanaan cedera di rumah, 2) meningkatkan keterampilan mitra dalam melakukan pertolongan pertama cedera pada anak. 


\section{METODE}

Berbagai permasalahan yang muncul di Puskesmas Ambacang Kuranji Padang dapat dikelola dengan melihat potensi yang dimiliki yaitu ketersediaan sumberdaya manusia, fasilitas pendukung, dan jasa layanan yang ditawarkan serta keberadaannya sebagai salah satu instansi pelayanan kesehatan di Kota Padang. Permasalahan saat ini adalah mengatasi pengetahuan dan keterampilan dalam mengidentifikasi cedera pada anak dan upaya antisipasi yang dapat dilakukan di rumah. Oleh karena itu, dosen di Fakultas Keperawatan berkewajiban melakukan meberikan pendidikan dan pelatihan sesuai dengan kebutuhan keluarga yang memiliki balita.

Untuk itu aktivitas yang akan dilakukan adalah kegiatan pelatihan bertujuan untuk menyampaikan teori dan aplikasi teori oleh narasumber tentang cedera pada anak dan upaya antisipasi cedera. Kualifikasi narasumber dalam pelatihan ini adalah:

a. Latar belakang pendidikan minimal S2.

b. Memiliki pengalaman untuk melatih tentang pelayanan kesehatan.

c. Berasal dari instansi yang berbadan hukum di bawah lingkungan Kementerian Kesehatan Republik Indonesia dan Kementerian Riset, Teknologi dan Pendidikan Tinggi.

Materi yang diberikan adalah defenisi, klasifikasi cedera dan identifikasi masalah atau lingkungan yang menimbulkan cedera pada anak serta upaya pencegahan dan penatalaksanaan cedera di rumah. Bentuk kegiatan adalah ceramah dan diskusi, role play, demonstrasi dan redemonstrasi.

Pelaksanaan kegiatan terdiri atas 4 tahap, yaitu persiapan, pelaksanaan dan pengawasan, evaluasi kegiatan, dan rencana tindak lanjut. Pada tahapan persiapan aktivitas yang dilakukan adalah membentuk tim task force, sosialisasi program pada semua unsur terkait, pembagian tugas, menjalin kerjasama dengan pihak terkait, menetapkan narasumber, dan penentuan tempat dan waktu pelatihan. Tahap berikutnya adalah pelaksanaan. Adapun metode pelaksanaan kegiatan yang ditawarkan untuk mengatasi permasalahan tersebut meliputi:

Pada tahap evaluasi dilakukan aktivitas yang bertujuan untuk menilai keberhasilan program terhadap indikator kinerja yang ditetapkan dan menilai kesesuaian antara tujuan dengan output yang dihasilkan. Evaluasi dilakukan setelah semua program selesai dilakukan oleh tim task force.

Pada tahap akhir, aktivitas yang akan dilakukan adalah menyusun perencanaan tindak lanjut apabila dari hasil evaluasi terdapat kendala yang mengakibatkan indikator kinerja tidak tercapai sesuai dengan target yang ditentukan.

\section{HASIL DAN PEMBAHASAN}

Kegiatan yang telah dilaksanakan berupa edukasi kesehatan pada kelompok sasaran yaitu ibu-ibu yang memiliki anak balita. Topik edukasi kesehatan yang disampaikan adalah pertolongan pertama kecelakaan pada anak di rumah. Lokasi kegiatan ini adalah di Mesjid Al-Ikhlas, Jl. Moh. Yunus, Anduring Kecamatan Kuranji Kota Padang. Waktu pelaksanaan kegiatan bertepatan dengan Hari Pahlawan Nasional yaitu 10 November 2018 pukul 09.00 sd 14.00 wib. 
Berikut ini merupakan uraian tahapan kegiatan edukasi kesehatan:

1. Tahap Persiapan

Pada tahap awal persiapan, ketua beserta anggota tim melakukan identifikasi masalah pada kelompok ibu-ibu yang memiliki balita di wilayah kerja Puskesmas Ambacang Padang. Pengidentifikasian masalah ini menggunakan metode wawancara dengan pihak Puskesmas dan rekapitulasi data di unit emergensi Puskesmas. Dari hasil tersebut diperoleh bahwa kejadian tersedak benda asing, mimisan, pusing, luka bakar ringan, luka sayat, dan sengatan listrik merupakan kejadian yang sering dialami oleh anak di rumah. Dengan demikian, tercapai sebuah kesepakatan antara Ketua dan pihak Puskesmas untuk mengadakan edukasi kesehatan dalam upaya mengenali dan mengatasi masalah tersebut.

Selanjutnya, tim melakukan pengembangan proposal kegiatan dan meyampaikan ke Unit Penelitian dan Pengabdian Masyarakat (UP2M) Fakultas Keperawatan Universitas Andalas agar dapat didanai. Tahap berikutnya adalah menetapkan kualifikasi narasumber, materi edukasi, dan melakukan kontak dengan narasumber untuk penetapan jadwal kegiatan. Tahap akhir persiapan adalah melakukan pengurusan administrasi ke lokasi kegiatan dan diskusi teknis kegiatan bersama dengan mahasiswa praktik profesi Keperawatan Komunitas.

\section{Tahap Pelaksanaan}

Pada tahap ini, ketua beserta anggota tim melakukan persiapan selama satu minggu sebelum pelaksanaan berupa persiapan alat dan bahan edukasi seperti powerpoint dan booklet edukasi kesehatan, kuesioner pre dan post test, spanduk, undangan kepada peserta, infokus dan layar, serta alat pengeras suara. Dalam menyebarkan undangan kepada peserta, tim melakukan koordinasi dengan kader kesehatan yang ada di wilayah mitra.

Pelaksanaan kegiatan diawali dengan registrasi peserta, pembukaan yang disampaikan oleh Kepala Puskesmas Ambacang ibu dr. Weni Fitria Nazulis dan Dekan yang diwakili oleh Wakil Dekan III ibu Dr. Ns. Meri Neherta, S.Kep., M.Biomed. Setelah pembukaan, dilanjutkan dengan mengidentifikasi pengetahuan peserta mengenai topik edukasi menggunakan kuesioner yang terdiri atas 25 pertanyaan dengan empat pilihan jawaban (kuesioner terlampir) selama 15 menit. Pada saat pre-test terdapat satu orang peserta yang kesulitan dalam membaca kuesioner karena tidak menggunakan alat bantu (kaca mata) sehingga tim membantu dalam membacakan pertanyaan dan pilihan jawaban.

Kegiatan berikutnya adalah penyampaian materi oleh narasumber (Ns. Dwi Novrianda, S.Kep., M.Kep.) selama 60 menit. Metode penyampaian materi berupa ceramah, diskusi, dan demonstrasi tentang cara pertolongan pertama kecelakaan di rumah yang dapat dilakukan oleh ibu. Demonstrasi yang dilakukan adalah penanganan tersedak pada anak menggunakan teknik Heimlich dan bayi menggunakan teknik tepukan punggung dan dorongan dada (back blow dan chest trust). Selain itu, pemateri juga memperlihatkan kotak Pertolongan Pertama pada Kecelakaan (P3K) dan komponen yang harus ada dalam kotak tersebut serta alat pelindung diri (APD) yang dapat disediakan di rumah. Pada saat diskusi dua orang ibu menanyakan perihal penanganan pingsan dan penyebab seorang anak pingsan. Setelah penyampaian materi, tim mengukur kembali tingkat pengetahuan peserta menggunakan instrument yang sama selama 15 menit. 


\section{Tahap Evaluasi}

Pada tahap evaluasi, terdapat tiga bentuk kegiatan yaitu :

a. Evaluasi pelaksanaan edukasi kesehatan

Pelaksanaan kegiatan dievaluasi menggunakan pendekatan peningkatan kualitas (a quality improvement approach) berdasarkan pada struktur, proses dan kriteria hasil.

\section{Evaluasi struktur}

Tim menyiapkan materi edukasi dengan menggunakan berbagai literature berupa buku teks dan artikel jurnal, sehingga tersusunlah secara sistematis slide powerpoint dan booklet yang mudah dipahami oleh peserta dari berbagai usia dan tingkat pendidikan (Gambar 1). Selanjutnya tim juga mempersiapkan instrument yang dapat mengukur tingkat pengetahuan peserta tentang materi. Dalam pembuatan instrument ini tim memodifikasi instrument P3K Rahmi Garmini (https://www.academia.edu/31530308/SOAL_PRE_POST_P3K) dan Cahya Aminah.

\section{Evaluasi proses}

Pelaksanaan kegiatan mengalami beberapa hambatan, di antaranya ketepatan waktu mulai pelaksanaan kegiatan tidak sesuai dengan yang direncanakan. Hal ini merupakan permasalahan umum yang ditemui di masyarakat dalam menggerakkan masyarakat untuk mengikuti jadwal yang sesuai. Akan tetapi, peserta memiliki antusiasme dan motivasi yang baik untuk mengikuti kegiatan karena edukasi yang diberikan bermanfaat dalam meningkatkan pengetahuan ibu-ibu dalam mengenali tanda cedera dan upaya melakukan pertolongan pertama cedera sebelum bantuan medis datang.

Tabel 1. Distribusi frekuensi pengetahuan responden pada saat pre-test dan post-test

\begin{tabular}{|c|c|c|c|c|c|}
\hline \multirow[t]{2}{*}{ No. } & \multirow[t]{2}{*}{ Pertanyaan } & \multicolumn{2}{|c|}{ Pre-test } & \multicolumn{2}{|c|}{ Post-test } \\
\hline & & Benar & Salah & Benar & Salah \\
\hline 1. & Definisi pertolongan pertama & 50 & 50 & 20 & 80 \\
\hline 2. & Kepanjangan P3K & 100 & 0 & 100 & 0 \\
\hline 3. & Tujuan P3K & 70 & 30 & 100 & 0 \\
\hline 4. & Kegiatan P3K & 90 & 10 & 100 & 0 \\
\hline 5. & Penanganan luka lecet & 90 & 10 & 100 & 0 \\
\hline 6. & $\begin{array}{l}\text { Bukan cara pertolongan } \\
\text { pertama }\end{array}$ & 20 & 80 & 90 & 10 \\
\hline 7. & Efek luka bakar & 80 & 20 & 50 & 50 \\
\hline 8. & Isi kotak P3K & 80 & 20 & 100 & 0 \\
\hline 9. & $\begin{array}{l}\text { Alasan ketepatan pertolongan } \\
\text { pertama }\end{array}$ & 70 & 30 & 100 & 0 \\
\hline 10. & $\begin{array}{l}\text { Cara memberikan pertolongan } \\
\text { pertama }\end{array}$ & 90 & 10 & 90 & 10 \\
\hline 11. & Penanganan anak pingsan & 60 & 40 & 100 & 0 \\
\hline 12. & Definis APD & 40 & 60 & 100 & 0 \\
\hline 13. & Isi APD & 60 & 40 & 100 & 0 \\
\hline 14. & Penanganan luka & 30 & 70 & 90 & 10 \\
\hline 15. & RJP & 70 & 30 & 80 & 20 \\
\hline
\end{tabular}




\begin{tabular}{|l|l|c|c|c|c|}
\hline 16. & Terkilir otot & 0 & 100 & 10 & 90 \\
\hline 17. & Penyebab luka bakar & 0 & 100 & 80 & 20 \\
\hline 18. & Penyebab pingsan & 10 & 90 & 20 & 80 \\
\hline 19. & Zat beracun & 30 & 70 & 90 & 10 \\
\hline 20. & Penanganan syok & 40 & 60 & 60 & 40 \\
\hline 21. & Penanganan tersedak 1 & 10 & 90 & 70 & 30 \\
\hline 22. & Penanganan tersedak 2 & 0 & 100 & 0 & 100 \\
\hline 23. & Penanganan tersedak 3 & 20 & 100 & 30 & 70 \\
\hline 24. & Penanganan tersedak 4 & 20 & 80 & 20 & 80 \\
\hline 25. & Penanganan tersedak 5 & & 20 & 80 \\
\hline
\end{tabular}

Tabel 2. Rata-rata skor pengetahuan peserta

\begin{tabular}{|l|c|c|c|}
\hline Skor pengetahuan & Mean & SD & Min-Maks \\
\hline Pre-test & 11.3 & 4.13 & $2-17$ \\
\hline Post-test & 17.6 & 2.67 & $15-23$ \\
\hline
\end{tabular}

Tabel 3. Perbedaan skor pengetahuan sebelum dan sesudah edukasi kesehatan

\begin{tabular}{|l|c|c|c|c|c|}
\hline & Beda mean & SD & T & df & p value \\
\hline $\begin{array}{l}\text { Pre-test } \\
\text { Post-test }\end{array}$ & 6.30 & 2.83 & 7.039 & 9 & 0.000 \\
\hline
\end{tabular}

$\underline{\text { Kriteria hasil }}$

a. Rata-rata skor pengetahuan sebelum edukasi kesehatan adalah 11,3 dengan nilai minimum 2 dan maksimum 17. Setelah dilakukan edukasi kesehatan terjadi peningkatan rata-rata skor sekitar 6.3 dengan nilai minimum 15 dan maksimum 23 (rentang skor 0-30) (tabel 1 dan 2). Terdapat peningkatan pengetahuan peserta antara sebelum dan setelah edukasi kesehatan secara signifikan ( $\mathrm{p}$ value 0,000 ). Hal ini dapat terlihat dari hasil pengujian statistik menggunakan paired t-test (tabel 3).

b. Penyusunan laporan pelaksanaan kegiatan dan publikasi kegiatan

Kegiatan ini telah dipublikasikan pada koran lokal yaitu Padang Ekspress tanggal 13 November 2018 halaman 14.

c. Penyusunan rencana tindak lanjut

Rencana tindak lanjut disusun agar kegiatan ini dapat berkelanjutan dan tercapainya pemberdayaan masyarakat secara optimal. Pada akhir kegiatan, diperoleh suatu kesepakatan antara Bagian Keperawatan Anak-Maternitas Fakultas Keperawatan Universitas Andalas, Puskesmas Ambacang, dan kader kesehatan di wilayah mitra untuk melangsungkan kerja sama peningkatan wawasan dan keterampilan kelompok ibu-ibu dalam penanganan cedera dan kegawatan medis di rumah. 
Website. http://hilirisasi.lppm.unand.ac.id e-ISSN: 2621-7198
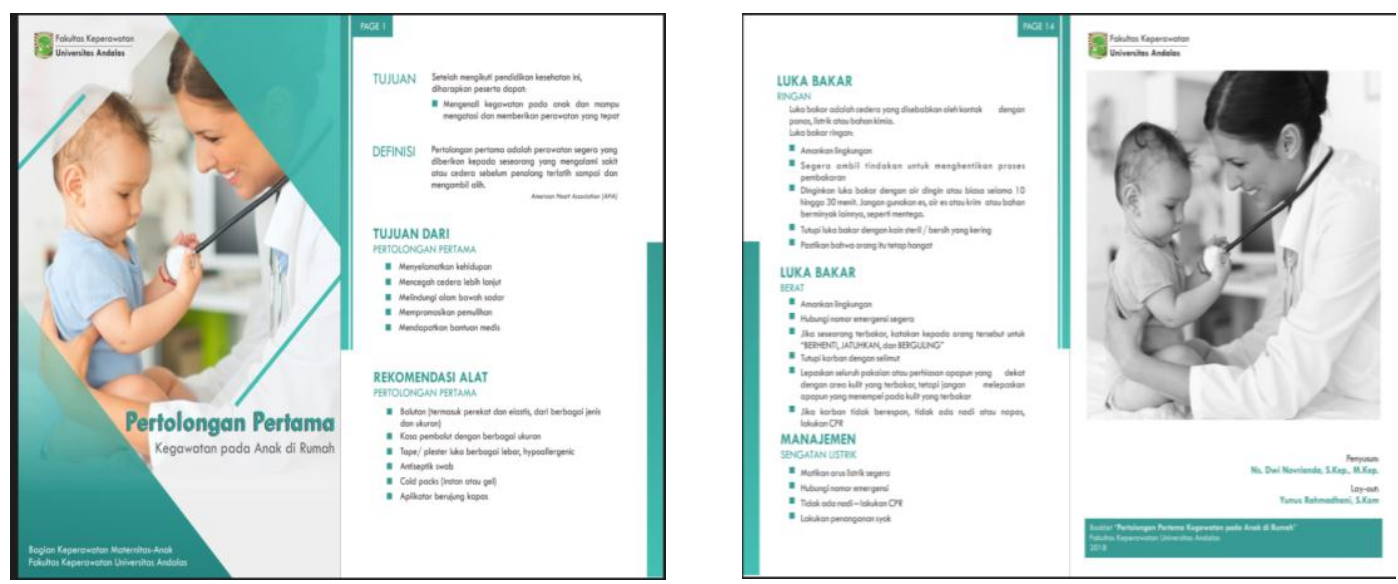

Gambar 1. Booklet edukasi kesehatan "Pertolongan Pertama Kegawatan pada Anak di Rumah"
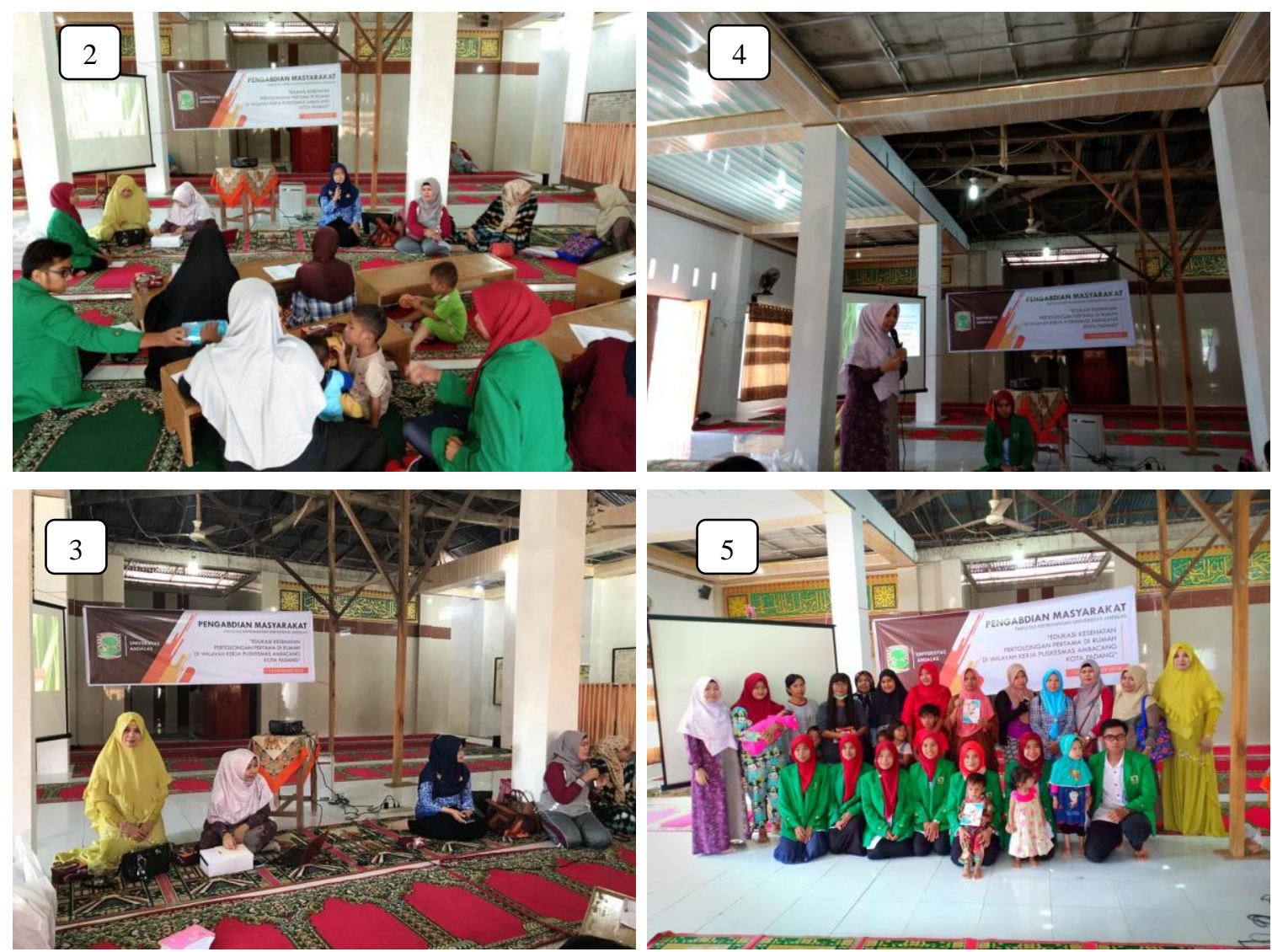

Gambar 2 sampai dengan 5. Pembukaan, Kata Sambutan, Pemberian materi, Foto bersama 


\section{KESIMPULAN DAN SARAN}

Berdasarkan kegiatan yang telah dilakukan maka dapat diambil beberapa kesimpulan, yaitu: 1) Peserta dapat memahami dan mengenali tanda-tanda kegawatan medis dan cedera pada anak, 2) Peserta dapat melakukan upaya pertolongan pertama yang dapat dilakukan di rumah untuk mengatasi kegawatan medis dan cedera pada anak sampai kedatangan pertolongan medis, 3) Peserta mengetahui nomor emergensi yang dapat dihubungi untuk wilayah kota Padang yaitu 118 dan fasilitas pelayanan kesehatan terdekat dari rumah. Di masa mendatang, perlu dilakukan edukasi kesehatan, demonstrasi dan redemonstrasi penanganan tersedak dan resusitasi jantung paru pada bayi dan anak, serta modifikasi lingkungan rumah yang aman bagi anak.

\section{UCAPAN TERIMA KASIH}

Penulis mengucapkan terima kasih sedalamnya kepada peserta edukasi kesehatan, Pimpinan dan Perawat Puskesmas Ambacang serta Kader Kesehatan RW IV Kelurahan Anduring yang telah berpartisipasi aktif dalam kegiatan. Penulis juga menyampaikan terima kasih sebesar-besarnya kepada Unit Penelitian dan Pengabdian Masyarakat (UP2M) Fakultas Keperawatan Universitas Andalas yang telah mendanai dan memfasilitasi pelaksanaan kegiatan pelatihan ini

\section{DAFTAR PUSTAKA}

Ablewhite, J., McDaid, L., Hawkins, A., Peel, I., Goodenough, T., Deave, T., Stewart, J., Watson, M., and Kendrick, D. 2015. Approaches used by parents to keep their children safe at home: a qualitative study to explore the perspectives of parents with children aged under five years. BMC Public Health, 15:983-993. DOI 10.1186/s12889-015-2252-x.

Behrman, R.M., Kliegman, A.M.A. 2012. Ilmu Kesehatan Anak Nelson. Volume 3 Edisi 15. EGC, Jakarta.

Depkes RI. 2006. Buku Pedoman Sumber Daya Manusia Kesehatan. Depkes RI, Jakarta.

Hockenberry, M. J., \& In Wilson, D. 2015. Wong's Nursing Care Of Infants And Children. $10^{\text {th }}$ Edition. St. Louis, Elsevier, Missouri.

Potter, P. A., Perry, A. G., In Hall, A., \& In Stockert, P. A. 2009. Fundamentals of Nursing. $7^{\text {th }}$ Edition. St. Louis, Missouri : Mosby Elsevier.

Supartini, Y. 2012. Buku Ajar: Konsep Dasar Keperawatan Anak. EGC, Jakarta.

World Health Organization. 2008. Injury: A Leading Cause of the Global Burden of Diseases. WHO, Switzerland, Geneva. 